\title{
Embodied energy analysis of multi-storied residential buildings in urban India
}

\author{
S. Bardhan \\ Dept. of Architecture, Jadavpur University, India
}

\begin{abstract}
Today developing nations are witnessing an unprecedented pace of urbanization in the wake of industrialization and globalization. This is giving rise to an ever increasing demand for housing and infrastructure to support the growing population and its activities. Energy is the single-most significant driver of this urban development and buildings stand as the most visible expressions of this development. However, buildings are known to be highly energy intensive and considering energy supply from conventional sources, these buildings have substantial negative environmental impacts. While operational energy of buildings have been mapped and assessed for different building typologies and various climatic zones, the embodied energy captive in the building fabric has received relatively lesser attention. Thus, efforts towards energy management and conservation in building operations have sufficiently addressed the concerns and have been reflected in the many building-rating systems prevailing across the world, though there had been limited research in the field of embodied energy measurement of contemporary multi-storied residential buildings constructed with modern technology. This assumes more significance in view of today's energy constrained world where exhaustive database on energy expended through all possible avenues need to be recorded in order to optimize and regulate this capital energy component of the building industry. In this backdrop, the present paper discusses the process and results of embodied energy analysis of one such typical multi-storied residential apartment of steel reinforced concrete construction in the metropolitan city of Calcutta (now Kolkata) in India and compares it with reported findings of some similar researches in Japan and India.
\end{abstract}

Keywords: urban buildings, embodied energy, construction materials 


\section{Introduction}

The present paper is set in the background of the ongoing debate and research activities related to the two critical and apparently mutually conflicting pillars of sustainability - Energy and Environment. IPCC fourth assessment report of WGIII [1] identifies building sector with high mitigation potential and WGII [2] identifies urban areas as hotspots in terms of vulnerability. In developing countries where housing sector is going to see very fast growth rate with increasing income and fast urbanisation, this will have crucial implication for mitigation (emission whether at the construction stage or at operational stage) and adaptation.

Over several decades, the rate of increase of population has become principal drivers of urbanization. India's urban population is expected to rise from $28 \%$ to $40 \%$ of the total population by 2020 placing increased stress on the country's urban infrastructure. However this is relevant not only for India but for any developing country given the projection of United Nations that by 2030, six out of every ten people will live in towns and cities, resulting in an accelerated population density in these urban areas. This has a significant impact on land, water and eco-system. In a bid to provide housing to this increased population within limited physical spaces, the general trend of urban construction today is a predominant verticality. Although India does not figure in the hundred tallest completed buildings in the world, it is not far away either. High-rise constructions in all the metropolitan cities of India have contributed to an increased total built-up area in the cities, which is also considered as real estate growth index or 'development' index. These buildings certainly help to have larger open spaces for citizens while accommodating a higher residential density but also consume substantial energy per unit floor area. Even though historically India deployed the rich tradition of solar passive buildings and vernacular architecture that are harmonious with environment, urban India is adopting a more and more global architectural vocabulary and higher preference for conditioned spaces. This paradigm shift in building design and planning with change in technology and life-style has resulted in major consumption of global resources. A UNEP [3] study found out that taking into account its entire lifespan, a typical building worldwide is currently responsible for up to $25-40 \%$ of energy use, $30-40 \%$ of solid waste generation and $30-40 \%$ of global green house gas emissions. Several international research groups have identified the need of further investigations in areas related to energy efficiency in building sector, particularly from developing country perspectives and also the necessity of many more evaluation studies from these regions, especially from quantitative viewpoint. Even the World Business Council for Sustainable Development (WBCSD) has adopted a vision in which all buildings in the world will consume zero net energy by 2050 .

In view of the above, the current paper focuses on a study on capital energy consumption of urban multi-storied residential buildings with the objective of benchmarking and forming base-line information on the said area in Indian context. The green building rating systems, which are in popular practice today, 
concentrates on the operational and maintenance periods only. Seen from the environmental perspectives, it is this embodied energy in the buildings that are analogous to loans taken from the environment but are never ever repaid back.

Buildings are very complex systems varying with climatic conditions, usage and user aspirations (influencing decision-making and choice of building materials) while also engaging multiple engineering products, services and technology. Thus the embodied energy of a building system is a reflection of interplay between a wide range of diverse technical and human factors. Embodied energy analysis vis-à-vis operational energy can be interesting to study, as the latter is dependent on the building typology, type of construction and the occupants' behaviour. Thus, while embodied energy can be 11 times the annual operational energy for a two-storey brick and reinforced concrete (RC) residential building in India and 8 times for a low-rise apartment in UK [4], it is only 3.5 times for a three-storey brick and RC constructed tourist lodge in coastal India [5]. However, considering the entire life-cycle of the building, the operational energy far exceeds its embodied energy. Hence, as Cole and Kernan [6] point out that strategy for reducing life-cycle energy use of the building should begin by incorporating ways to reduce building operating energy; this is probably the reason why the current building rating systems concentrate on this aspect only. On the other hand, Vukotic et al.[7] rightly argues that construction of energy-efficient buildings is more energy intensive and therefore, building embodied energy will become increasingly significant with decreasing operational energy.

\subsection{Boundary conditions of the study}

The case study selected is a ground plus thirty-five-storey residential apartment building of steel and RC construction in the heart of the city of Kolkata in the Eastern Indian state of West Bengal. The study aims to assess its Embodied Energy (EE) i.e. energy consumed at the construction stage comprising of the following sub-stages:

i. Energy embedded in the body of the building in the form of the construction materials used

ii. Energy required to transfer these materials to the site of construction from the supply sources

iii. Energy consumed during actual erection of the structure involving the three 'M's: Materials, Machines and Man

In this study, however, out of the myriad materials normally used in a building, the evaluation has been kept limited to those having the largest stake in its erection. Emmanuel [8] rightly pointed out that the embodied energy of building materials will vary from one country to another, depending on the sources of energy used for manufacturing and climatic condition of that country. Thus limited availability of data on embodied energy of building materials in the Indian context was another reason for keeping the list of materials restricted to a major few. A previous study on embodied energy of smaller buildings with about 300- $400 \mathrm{Sq} \mathrm{m}$ built area in eastern India by Bardhan [5] and Bardhan et al [9] had earlier estimated the energy consumed at stage-ii i.e. in transportation of 
building materials to be only $1.85 \%$ of the embodied energy of the materials while that consumed during stage-iii is lesser - a mere $0.06 \%$ of the same. Together, these account for only $1.91 \%$ of the embodied energy of the materials. For a larger building, the figures lowered to $0.52 \%$ and $0.02 \%$ respectively. However, since the said study was conducted for buildings located $140 \mathrm{Km}$ from the nearest metropolis of Calcutta, the energy expended under transportation head was much more than that for erection. In contrary to this, urban buildings require more energy at stage-iii than at stage-ii since built areas are not only considerably higher but also have greater machine dependence. Hence the energy involved in transporting the building materials from supply source to site was not considered in this particular investigation as the case study is located at the heart of the city and the materials are already in stock with the building material suppliers irrespective of any particular construction.

Reddy and Jagadish [10] had estimated that when transportation energy is compared with respective production energy, it is negligible for high energy materials like cement and steel, though it is $4-8 \%$ in case of bricks and 400 $800 \%$ in case of aggregates. Thus, while acknowledging that the stage-ii component may have significant contribution in many cases, it was believed that this would be negligible with respect to the present study. The stage-iii component has been considered here by way of energy bills since the building stock is quite substantial and access to the energy bills of construction period was possible.

To summarize, this study considers the sum of the stage-i and stage-iii energy components to assess the embodied energy of the building that has already been locked within its fabric. It is deemed that the energy consumed per unit area of the building will give an idea of the constructional energy consumption pattern of today's multistoried residential buildings and help to formulate specific energy strategies towards this.

\subsection{Case- study: urban contemporary multi-storied building}

The case study is essentially a mixed-use development led by residential land use. It is popular for being one of the tallest residential building projects in and around Kolkata. Its thirty five-storey multi-family tower blocks are set in a site of 31.14 acres in a residential neighbourhood of South Calcutta. The tower blocks comprise of about 1600 nos. of apartments and a total built-up area of 310,173.22 Sq $\mathrm{m}$. The residential buildings share the site with a commercial complex and a secondary school along-with a recreational centre for the residents. It is in the process of further expansion, and when completed, the entire project will have a total built up area of $400,587 \mathrm{Sq} \mathrm{m}$.

\subsection{Materials, machines and manpower used in the case- study}

The buildings under study were constructed during the period 2002-2009 and comprises of four tower blocks and the total built-up area of all the blocks together is more than three million square feet as stated above. It is primarily a reinforced cement concrete construction with other materials used being glass, 
steel, aluminium, timber/plywood, natural stones like granite/marble, ceramic/vitrified tiles and plaster of Paris. Ancillary materials include those needed for engineering services like PVC - electrical switch boxes and cable covers, copper cables, other metals like plumbing fittings, hardware, nails etc.

The machines involved in the construction were identified as a piling machine, tower crane, builders hoist, welding machine, bar-bending machine, hand drill, stone cutting and stone polishing machine, JCB for site clearing, earth cutting and excavation. Out of these, the piling machine and JCB were diesel driven, thus contributing differently to the energy head. The hours of operation of each machine varied between 8-10 hours with a maximum of 14 hours. The power rating multiplied by the number of hours of operation will give the actual electrical energy consumed and the diesel consumed may be derived from the fuel efficiency of the particular machine.

In terms of manpower, the site was used for housing the day labourers of an average of 1200 persons at any given time during the construction period, with a maximum peak of 2200 . This figure is important as the resident labourers stayed in labour quarters that had to be built prior to actual construction, used power and water for their duration of stay and also generated domestic waste. All such resource consumption would account to the building head and has to be considered as a part of its embodied energy foot-print.

\section{Embodied energy assessment}

\subsection{Energy embedded in the building by virtue of materials or stage $i$}

As mentioned earlier, only major materials like cement, sand, aggregate, bricks and structural steel reinforcement were considered as these data were readily available from the project office. However, glass and aluminum sections used for the external fenestrations and dimension stones used for floor finish were also included. The embodied energy coefficients used to calculate this were based on

Table 1: Quantity survey of materials.

\begin{tabular}{|c|l|c|}
\hline SI. No. & \multicolumn{1}{|c|}{ Materials } & Embodied Energy (GJ) \\
\hline 1 & Cement & 1207892.4 \\
\hline 2 & Stone chips & 38259.300 \\
\hline 3 & Sand & 46729.904 \\
\hline 4 & Bricks & 221531.268 \\
\hline 5 & Steel & 1361710 \\
\hline 6 & 6 mm Glass & 879.4128 \\
\hline 7 & Anodised Al (for exterior windows only) & 3437.449 \\
\hline 8 & Dimension Stones (marble/ granite) & 22941.016 \\
\hline \multicolumn{2}{|c|}{ Total Embodied Energy of the materials } \\
\hline & Total built up area $=310173.22$ Sq $\mathrm{m}$ \\
\hline \multicolumn{2}{|c|}{} \\
\hline
\end{tabular}


recent studies in India and New Zealand [10, 11]. The detailed calculations revealed that the embodied energy of all the residential blocks by virtue of major materials only is in the range of $2.9 \times 10^{6}$ Giga Joules (GJ), which comes to around $9.36 \mathrm{GJ} / \mathrm{Sq} \mathrm{m}$ of built-up area, as presented in Table 1.

\subsection{Energy consumed during building erection or stage iii}

For this assessment, two alternative approaches - top-down and bottom-up were considered. Both these methods are primarily concerned with the electrical energy used during the site construction work. The top-down approach considered the electrical load estimated by the developers and applied for from the electricity supply agency, which in this case was two nos. $500 \mathrm{kVA}$ metres i.e., a total of $1000 \mathrm{kVA}$. The second metre was applied when the first was found to be inadequate to supply power for the construction site. The bottom-up approach takes account of the energy bills of the site and were analyzed to obtain the actual power consumption over the entire construction period.

Based on data received from the project's office, the following considerations were used for the top-down assessment:

- $75 \%$ of the total electric load was used during the construction period.

- On an average, construction work continued for 12 hours a day and 350 days a year.

- Effective time of completion was six years.

The electrical energy consumed for construction per day was estimated as $(0.75 \times 1000 \times 12)=9000 \mathrm{kWh}$ or $32.4 \mathrm{GJ}(1 \mathrm{kWh}=0.0036 \mathrm{GJ})$. With 350 working days, the annual energy used for construction was evaluated at approximately 11340 GJ. For the entire construction period of six years, this worked out to be $68040 \mathrm{GJ}$ for all the building blocks, which translates to 0.22 $\mathrm{GJ} / \mathrm{Sq} \mathrm{m}$ of building area.

For the second method, the energy bills (available from 2002 third quarter to 2009 first quarter i.e. 6.75 years) were obtained from the developers' office and the monthly electrical expenses were converted into energy consumed in KiloWatt-Hour $(\mathrm{kWh})$ by dividing this value with the unit energy rate, considered here to be INR 3.91 as per available contemporary data. The energy consumption values were again converted in Giga Joule $(1 \mathrm{kWh}=0.0036 \mathrm{GJ})$. The annual energy consumption throughout the construction period is depicted in the following figure.

In Figure 1 the graph shows the annual energy consumption pattern during construction. Total energy consumed for the entire project between 2002 third quarter to 2009 first quarter was found to be 56,513.20 GJ. Considering that erection of the blocks was completed by 2009 first quarter, embodied energy per unit area constructed comes to $0.18 \mathrm{GJ} / \mathrm{Sq} \mathrm{m}$.

Thus, according to the top-down approach, the energy spent for building erection is about $0.22 \mathrm{GJ} / \mathrm{Sq} \mathrm{m}$ while that by the bottom-up method is 0.18 $\mathrm{GJ} / \mathrm{Sq} \mathrm{m}$, with approximately a $20 \%$ difference between the two. Since both are based on electrical energy consumption, an average of the two i.e. $0.2 \mathrm{GJ} / \mathrm{Sq} \mathrm{m}$ 


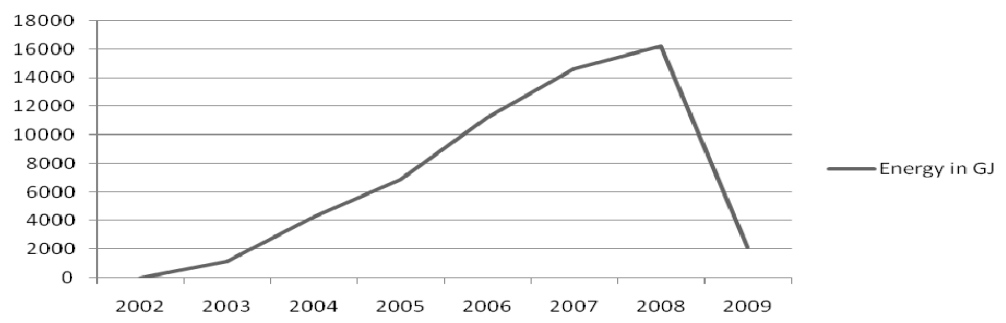

Figure 1: Annual energy consumption pattern during construction.

has been considered for the purpose of EE estimate. It is to be noted that the electrical energy consumed by the 1200 resident labourers are also included in this. However, data on the quantity of fossil fuel used during construction for back-up power supply, machineries and man power were not recorded by the project office and therefore, are not reflected in the figures.

\subsection{Total embodied energy of the building stock}

Adding the embodied energy of its major material constituents as found earlier, the total constructional embodied energy per unit area of these buildings works out to be around $9.56 \mathrm{GJ} / \mathrm{Sq} \mathrm{m}$. It is important to mention here that this is, by all means, a conservative estimate approach and represents a much lower figure than the actual.

\section{Results and discussions}

The embodied Energy Foot-print of the contemporary urban residential building studied and presented in this paper and involving only major construction materials and building erection is $9.56 \mathrm{GJ} / \mathrm{Sq} \mathrm{m}$. As stated earlier, the actual figure is expected to be much higher when all the other building materials are taken into account. An analysis of contribution of different stages to the total embodied energy of the building was carried out and Table 2 presents the result. It shows the construction materials to have a whopping $98 \%$ stake in the building's total embodied energy and the actual erection to be only about $2 \%$ of

Table 2: $\quad$ Contribution of different stages to building's EE.

\begin{tabular}{|c|l|c|c|}
\hline Sl. No. & \multicolumn{1}{|c|}{ Materials } & $\begin{array}{c}\text { Embodied Energy } \\
(\mathbf{G J} / \mathrm{Sq} \text { m) }\end{array}$ & $\begin{array}{c}\text { \% contribution to } \\
\text { EE }\end{array}$ \\
\hline 1 & $\begin{array}{l}\text { Stage-i: Total Embodied } \\
\text { Energy (EE) of the materials }\end{array}$ & $9.36 \mathrm{GJ} / \mathrm{Sq} \mathrm{m}$ & $98 \%$ \\
\hline 2 & $\begin{array}{l}\text { stage-iii: Energy consumed } \\
\text { during actual erection of the } \\
\text { building }\end{array}$ & $0.2 \mathrm{GJ} / \mathrm{Sq} \mathrm{m}$ & $2.0 \%$ \\
\hline & Total building EE & $9.56 \mathrm{GJ} / \mathrm{Sq} \mathrm{m}$ & $100 \%$ \\
\hline
\end{tabular}


that of the materials. This corroborates the previous study results that also found the EE of construction materials to be the major contributing factor to the building's EE, compared to their transportation to site and actual erection.

Further investigation was made to understand the contribution of individual construction materials to their collective energy head as presented in Table 3 .

Table 3: $\quad$ Contribution of different materials to building's EE.

\begin{tabular}{|c|l|c|}
\hline Sl. No. & \multicolumn{1}{|c|}{ Materials } & $\begin{array}{c}\text { Percentage contribution } \\
\text { to EE }\end{array}$ \\
\hline 1 & Cement & $41.6 \%$ \\
\hline 2 & Stone chips & $1.32 \%$ \\
\hline 3 & Sand & $1.6 \%$ \\
\hline 4 & Bricks & $7.64 \%$ \\
\hline 5 & Steel & $46.9 \%$ \\
\hline 6 & 6 mm Glass & $0.03 \%$ \\
\hline 7 & Anodised Al & $0.11 \%$ \\
\hline 8 & Stone finishing & $0.8 \%$ \\
\hline & Total Embodied Energy (EE) of the materials & $100 \%$ \\
\hline
\end{tabular}

Table 4: Comparative embodied energy measures of different types of constructions.

\begin{tabular}{|c|c|c|c|c|}
\hline SI. No. & Countries & Building types & $\begin{array}{l}\text { Embodied } \\
\text { Energy } \\
\text { (GJ/Sq m) }\end{array}$ & $\begin{array}{l}\text { Area } \\
(\text { Sq m) }\end{array}$ \\
\hline \multirow[t]{3}{*}{1} & India [10] & Eight storey conventional building & 4.21 & 5120 \\
\hline & & $\begin{array}{c}\text { Double storey conventional } \\
\text { building with load bearing walls }\end{array}$ & 2.92 & 149.5 \\
\hline & & $\begin{array}{l}\text { Double storey building with soil- } \\
\text { cement block and filler slab roof }\end{array}$ & 1.61 & 160.5 \\
\hline 2 & $\begin{array}{l}\text { New Delhi, } \\
\text { India [12] }\end{array}$ & Adobe house & 3.8 & 120 \\
\hline \multirow[t]{3}{*}{3} & India [13] & $\begin{array}{c}\text { Single storey } \\
\text { Load-bearing structures }\end{array}$ & $5-4.1$ & $50-200$ \\
\hline & & $\begin{array}{c}\text { Double storey } \\
\text { Load-bearing structures }\end{array}$ & $4.2-3.7$ & $50-200$ \\
\hline & & $\begin{array}{l}\text { Four-storey reinforced cement } \\
\text { concrete (RCC) buildings }\end{array}$ & $4.3-3.1$ & $50-200$ \\
\hline \multirow[t]{3}{*}{4} & Japan [14] & $\begin{array}{l}\text { Multi-family steel reinforced } \\
\text { concrete (SRC) houses }\end{array}$ & $8-10$ & - \\
\hline & & Wooden single-family houses & 3 & - \\
\hline & & $\begin{array}{l}\text { Lightweight steel structure single- } \\
\text { family houses }\end{array}$ & 4.5 & - \\
\hline 5 & $\begin{array}{l}\text { Current } \\
\text { study: } \\
\text { Kolkata, } \\
\text { India }\end{array}$ & $\begin{array}{l}\text { Multi-family steel reinforced } \\
\text { concrete (SRC) houses }\end{array}$ & 9.56 & $3 \times 10^{5}$ \\
\hline
\end{tabular}


Quite predictably, steel and cement topped the list, together contributing to $88.5 \%$ of the total. A lesson that can be learnt from this study is how to reduce the embodied energy of these materials at the production stage itself, so that the energy locked in these materials and subsequently in the buildings can be considerably minimized.

This finding has been compared with that of different types of buildings/ constructions as reported in various researches carried out in Asian countries in the last fifteen years.

It is interesting to note that the multi-family steel reinforced concrete (SRC) houses studied by Suzuki et al [14] found the embodied energy to be 8-10 GJ way back in 1995, which is closer to the findings of the current study. Whether technology improvement has led to energy efficiency in constructions remains a matter of further investigation. However, it is hoped that more and more researches would focus on this area for a wide range of building and construction typologies in different climatic regions to optimize and regulate the energy consumed at the construction stage of the building, much like what is already in voluntary practice for its operation and maintenance stage and finally, arrive at benchmarking the capital energy investment.

\section{Conclusions}

This paper presented a study on the embodied energy assessment of contemporary urban multi-storied residential buildings in the busy metropolis of Calcutta (now Kolkata) in eastern India. Data was collected from field survey and project office to a large extent and the missing links were assumed on the basis of prevalent practice. It was found that

- The embodied energy of major construction materials contribute to about $98 \%$ of the building's total embodied energy and steel and cement are the main contributors to this head.

- Energy involved in actual erection and assembly on site is a meager $2 \%$ negligible compared to that embedded in the materials itself.

- The EE of such a building was found to be about 9.56 GJ per Sq $\mathrm{m}$ of the building, which is quite comparable to similar research findings.

The result of this study is expected to help create benchmarking of capital energy consumption in building construction in contemporary urban India. This is further important as the embodied energy of rapidly growing Indian cities as well as proposed urban centres can also be estimated based on their building stock and real estate growth indices, along with their corresponding carbon emission contributions. The main challenge is to link this with the sustainable limits of urbanization to assist our decision makers in matters of urban development, energy issues and actions on climate change. 


\section{Acknowledgement}

The author is grateful to All India Council for Technical Education (AICTE) for its financial support in carrying out this study.

\section{References}

[1] IPCC, Climate Change 2007: Mitigation. Contribution of Working Group III to the Fourth Assessment Report of the Intergovernmental Panel on Climate Change [Metz, B., Davidson, O.R., Bosch, P.R., Dave, R., Meyer, L.A. (eds)], Cambridge University Press, Cambridge, United Kingdom and New York, NY, USA.

[2] IPCC, Climate Change 2007: Impacts, Adaptation and Vulnerability. Contribution of Working Group II to the Fourth Assessment Report of the Intergovernmental Panel on Climate Change, [M.L. Parry, O.F. Canziani, J.P. Palutik of, P.J. van der Linden and C.E. Hanson, (eds.)].Cambridge University Press, Cambridge, UK.

[3] United Nations Environment Program (UNEP) and Division of Technology Industry and Economics (DTIE), Eco-house Guidelines, 2006, pp. 5-6.

[4] http://www.newagepublishers.com/samplechapter/001378.pdf [Accessed 3rd Nov 2010, 22:34]

[5] Bardhan, S., Carbon Foot-Print Studies and Sustainable Architectural Concepts for Coastal Eco-Tourism, unpublished Doctoral thesis, Jadavpur University, 2008.

[6] Cole Raymond J. and Kernan Paul C., Life-cycle energy use in office buildings (Abstract), Building and Environment, 31(4), 1996, 307-317.

[7] Vukotic L., Fenner R. A. and Symons K., Assessing embodied energy of building structural elements (Abstract), Proceedings of the ICE Engineering Sustainability, 163(3), 2010, 147 -158.

[8] Emmanuel R, Estimating the environmental suitability of wall materials: preliminary results from Sri Lanka, Building and Environment, 39(10), 2004, 1253-1256.

[9] Bardhan, S., Chattopadhyay, M. and Hazra, S., Quantifying Environmental Sustainability of Buildings through its Carbon Foot-Print: An Analytical Approach, Journal of Civil Engineering and Architecture, 4(1), 2010, 2034.

[10] Reddy Venkatarama B.V. and Jagadish K.S., Embodied energy of common and alternative building materials and technologies, Energy and Buildings, 35(2), 2003, 129-137.

[11] Embodied Energy Coefficients, New Zealand, http://www.victoria.ac.nz /cbpr/documents/pdfs/ee-coefficients.pdf [Accessed 3rd Nov 2010, 21:30]

[12] Shukla A., Tiwari G. N. and Sodha M. S., Embodied Energy Analysis of Adobe House, Renewable Energy, 34(3), 2009, 755-761. 
[13] Debnath A., Singh S. V. and Singh Y. P., Comparative assessment of energy requirements for different types of residential buildings in India, Energy and Buildings 23(2), 1995, 141-146.

[14] Suzuki M., Oka T. and Okada K., The estimation of energy consumption and $\mathrm{CO}_{2}$ emission due to housing construction in Japan, Energy and Buildings, 22(2), 1995, 165-169. 